\title{
Length of stay in urban areas of circular migrants from the mountainous areas in China
}

\author{
TAN Ming-hong1 (D) http://orcid.org/oooo-0oo2-4945-7744; e-mail: tanmh@igsnrr.ac.cn

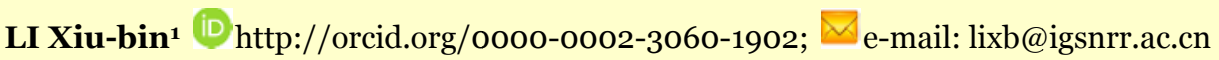

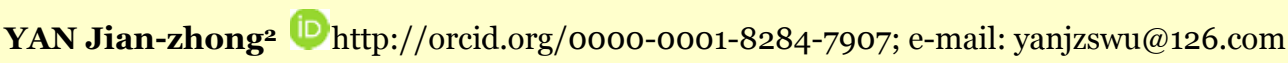 \\ XIN Liang-jie ${ }^{1}$ (D) http://orcid.org/oooo-ooo2-5163-9256; e-mail: xinlj@igsnrr.ac.cn \\ SUN Lai-xiang3 iD http://orcid.org/oooo-0002-6025-0242; e-mail: lsun123@umd.edu \\ 1 Key Laboratory of Land Surface Pattern and Simulation, Institute of Geographic Sciences and Natural Resources \\ Research, Chinese Academy of Sciences, Beijing100101, China \\ 2 College of Resources and Environment, Southwest University, Chongqing 400715, China \\ 3 Department of Geographical Sciences, University of Maryland, College Park, MD 20742, USA
}

Citation: Tan MH, Li XB, Yan JZ, et al. (2016) Length of stay in urban areas of circular migrants from the mountainous areas in China. Journal of Mountain Science 13(5). DOI: 10.1007/s11629-015-3477-y

(C) Science Press and Institute of Mountain Hazards and Environment, CAS and Springer-Verlag Berlin Heidelberg 2016

\begin{abstract}
Currently, there is limited literature dealing with the length of stay of circular migrants in urban areas (LSCMU), although many studies have discussed the phenomenon of migration and the determinants of migration. This study attempts to fill that gap using survey data from the mountainous areas of Chongqing, Southwest China. From a comparative perspective, this study divided workers into two groups (a young group aged between 16 and 35 years and an old group aged between 36 and 65 years). The average LSCMU values for the young and old groups were 225 days and 174 days, respectively. Two multi-regression models were used to estimate the determinants of LSCMU in the two groups. The results showed that LSCMU was closely related to individual factors in both groups, including gender, age and job training. Family and community factors, including household size, arable land per capita and the distance from market, had much weaker effects on the dependent variable, especially in the older group. It was noticeable that job training had significant positive effects on LSCMU in both groups; these
\end{abstract}

Received: 11 February 2015

Revised: 6 June 2015

Accepted: 24 August 2015 findings have special implications for the urbanization process in China.

Keywords: Circular migrants; Urban; Mountain areas; China

\section{Introduction}

In many parts of the world, a large proportion of the urban population has migrated from rural areas (Chang et al. 2011). The massive migration is related to many factors, such as better job opportunities and higher incomes in urban areas (Silveira et al. 2006; Thissen et al. 2010; Easterlin et al. 2011). In this context, the decision to stay or to go has become a prominent issue for rural inhabitants. For example, in Icelandic fishing and farming communities, about $70 \%$ of the population expected to migrate in 2003 (Bjarnasona and Thorlindsson 2006). At present, a plethora of literature has examined the phenomenon of migration or the proportion of emigrants in the 
total agricultural population and the determinants of migration. This has been done using various methods and tools, such as logistic regression and linear regression models (Seeborg et al. 2000; Zhang and Song 2003; Frayne 2004; Bjarnasona and Thorlindsson 2006; Liu2008; Gray 2009; Mulian et al. 2010).

In the existing literature, rural dwellers are often simply divided into two groups: migrants and non-migrants (Iacovou 2010). However, the process of migration is complicated and there are vast differences among migrants. Some migrants may never return home, while others (known as 'circular migrants') may go to and fro between urban and rural areas while maintaining close links with their villages of origin, especially in developing countries or regions, such as India, Namibia and East Africa (Elkan 1967; Cordell et al. 1996; Haan 1997; Frayne 2004). This linkage is central to the ability of poor migrants to survive (Frayne 2004).

Moreover, even among circular migrants, the differences are very significant: some stay in urban areas for a long time, whereas others stay only for a short time. However, to date, there has been very little literature that has discussed this issue.

In China, rural-urban migration may be more complicated, as the country has a two-track system where the rural society and urban society are divided by the hukou system (Knight and Gunatilaka 2010; Sun and Fan 2013). At present, although rural people have been allowed to move freely between urban areas and their home areas, most of them are only circular migrants; they are still denied permanent urban residency rights and the associated social benefits defined by the hukou system, including government-provided housing, medical treatment, children's education care and other amenities. These are more significant in large cities such as Beijing and Shanghai (Seeborg et al. 2000; Hu et al. 2011). Thus, due to expensive living and educational costs in urban areas, most migrants have to leave their children at home, while they circulate between urban and rural locations. Now, the central government of China is paying more specific attention to this type of migration and is emphasizing the possibility of decreasing the threshold to increase opportunities for circular migrants to become urban residents. For instance, some measures have been implemented, including the easing of hukou transfer to some cities and decreasing the educational costs for migrants' children. Thus, it is important to study the length of stay in urban areas of circular migrants, as the migrants who stay longer may have more opportunities or capacity to become urban residents.

In mountainous areas, owing to the poor natural environment and fewer job opportunities (Izquierdo and Grau 2009), outward migration has been widespread in many countries (Tzanopoulos et al. 2011). In existing studies, the effects and consequences of out-migration have been issues of increasing concern in mountainous areas (Gellrich and Zimmermann 2007). For instance, as a result of rural-urban migration, mountain regions are experiencing events characterized by agricultural land abandonment and natural forest recovery (Gellrich and Zimmermann 2007; Gray 2009; Izquierdo and Grau 2009; Sitzia et al. 2010). However, in these areas, rural-urban migration itself has been given little attention.

China is a mountainous country, with twothirds of its total land area covered by mountains, hills and plateaus. Because of the large population and long history of agricultural development, the pressure of population on agriculture is very high in many mountain areas, which has proved to be one of the important ecological and social problems in this country (Sitzia et al. 2010; Wang et al. 2012). In recent years, many rural workers in mountain areas have migrated to urban areas (Ding et al. 2005; Yu et al. 2013). This movement has reduced rural population pressure, which has attracted considerable attention of some scholars and the central and local governments (Zhang et al. 2000; Feng et al. 2003; Wang et al. 2007; Groom et al. 2009; Fang et al. 2014).

Chongqing comprises $77.8 \%$ mountainous areas and is a municipality directly under the administration of the central government (Figure 1). The total population has decreased by $6.5 \%$ during the period 2000-2010; this was the highest provincial rate of decrease in the country, according to the Sixth Census of China. As discussed above, few studies focus on the differences in the length of stay of circular migrants in urban areas (LSCMU) and factors behind migration; therefore, this study attempted to fill the gap, predominantly through the use of survey 
data from eight villages in Chongqing.

\section{Data and}

Methods

\begin{tabular}{lr}
\multicolumn{3}{c}{ In Chongqing, a } \\
survey of & 689 \\
households & in
\end{tabular}

Youyang and Wulong Counties in June 2012 provided the basis for examining rural-urban migration. All survey data referred to 2011. The survey covered eight villages and involved 2595 rural residents (Figure 1). We

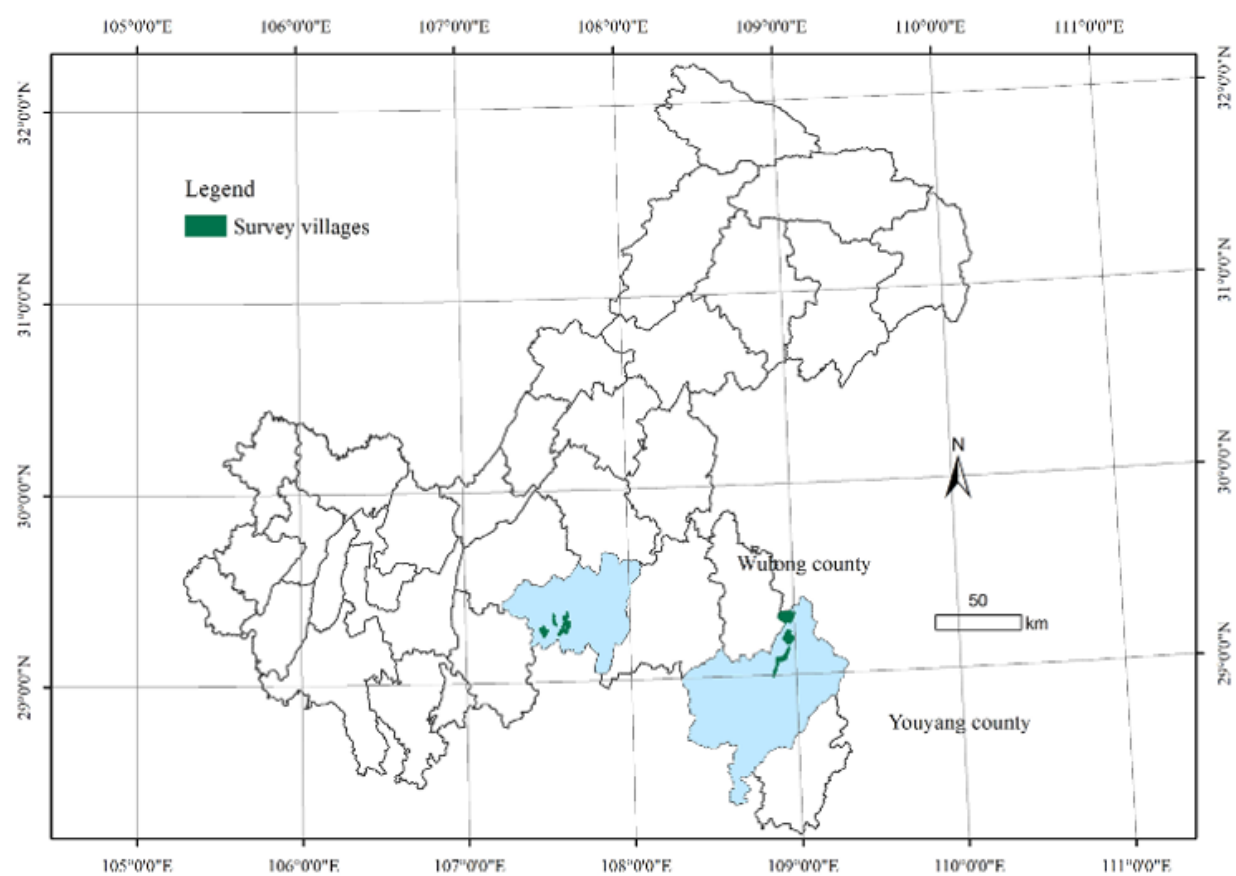

defined rural

labourers as those people aged between 16 and 65 years. Thus, a total of 1741 rural labourers were included from these eight villages. Of these, 608 had left home and worked elsewhere. In this study, 150 labourers who worked at home were selected randomly and regarded as control variables. Thus, 758 rural labourers were included in the final statistical analyses.

In each sampled household, two trained interviewers carried out a household questionnaire with either the head of the household or another knowledgeable adult, who also served as a proxy respondent for other adult household members and departed migrants.

In the study areas, the sample households were very poor, and annual income per capita was about than 7900 yuan (RMB). Household income can be divided into three parts: agricultural income, non-agricultural income and other income. Their respective shares were approximately $16 \%, 74 \%$ and $10 \%$ in 2011. Other income included subsistence assistance from government, gift money and presents from relatives.

Migration is often influenced by various factors at individual, household and community levels (Gray 2009). In this study, the survey also addressed these three aspects: individual features (e.g. age, gender), family features (e.g. size of housing, arable land area) and community characteristics (e.g. distance from school). In addition, there were considerable differences between the two counties, especially in terms of location, as Wulong County is much nearer to the large built-up areas of Chongqing (Figure 1).

Based on this explanatory framework, a set of indicators was selected to explain LSCMU (Table 1).

\subsection{Individual factors}

Individual characteristics involved six variables, which were very similar to those used in previous studies (Seeborg et al. 2000), for instance, age, gender, health status, marital status and education level (Table 1). The education of respondents was measured on a five-point scale (1, illiterate; 5, university degree). Similarly, the dependent variable of health status was measured on a four-point scale (Table 1).

With regard to the study area, workers often learn skills from vocational schools or skilled workers (such as decorators, carpenters or cooks), which may influence the variation in LSCMU. Therefore, the variable of Training was included in this study (Table 1). 
Table 1 Description of all variables selected in this study

\begin{tabular}{|c|c|c|c|}
\hline Variable group & Code of variable & Unit & Meaning and definition \\
\hline \multirow{6}{*}{ Individual factors } & Gender & & Dummy variable, 1 for male; o otherwise \\
\hline & Healthy & & $\begin{array}{l}\text { Health status: from } 1=\text { better, } 2=\text { general, } 3=\text { poor health, to } 4 \\
=\text { worse }\end{array}$ \\
\hline & Age & years & \\
\hline & Education & & $\begin{array}{l}\text { Education level: } 1=\text { illiterate } ; 2=\text { primary school; } 3=\text { middle } \\
\text { school; } 4=\text { high school; } 5=\text { university degree }\end{array}$ \\
\hline & Training & & $\begin{array}{l}\text { Job training: } 1 \text { = formal training; } 2 \text { = trained by master workers; } \\
3=\text { no training }\end{array}$ \\
\hline & Marriage & & Dummy variable, 1 for those who are married; o otherwise \\
\hline \multirow{5}{*}{ Family factors } & Size & persons & \\
\hline & Arab_per & $\mathrm{m}^{2} /$ person & Arable land per capita \\
\hline & Parcel_A & $\mathrm{m}^{2}$ & The average area of all arable land parcels of a family \\
\hline & Hou_per & $\mathrm{m}^{2} /$ person & Housing area per capita \\
\hline & Share_H & & Dummy variable: 1 for two families sharing a house; o otherwise \\
\hline \multirow{3}{*}{ Community factors } & D_market & $\mathrm{km}$ & Distance from market \\
\hline & D_hospital & $\mathrm{km}$ & Distance from hospital \\
\hline & D_wood & $\mathrm{km}$ & Distance from places for collecting firewood \\
\hline County difference & County_code & & Dummy variable: 1 for Youyang county; o for Wulong county \\
\hline
\end{tabular}

Note: Dependent variable is LSCMU (days).

\subsection{Family factors}

Family context has close relationships with migration, such as household size and land area (Haan 1997; Gray 2009). We consider the family context mainly from three viewpoints: household size, arable land area per capita and the average parcel area of arable land (Table 1). Here, we introduce the variable of Parcel_A, as the other two variables are easily understood. In China, the household responsibility system requires the village collective to divide farmland according to household size (Hu et al. 2011) and guarantees that every household enjoys equal rights to the use of village land. Thus, a family often has some highyielding land parcels and some low-yielding ones, combined with some land parcels far from the house and some located nearby. Moreover, in the mountain areas, arable land parcels are very small. As a result, a household may own land parcels in more than ten places in the study area, which increases the difficulty of cultivation and may affect the decision of rural labourers to stay at home or leave.

In addition, housing reflects living conditions and the quality of life of rural residents. Here, two variables were designed: Hou_per (housing area per capita) and Share_H (Table 1). Share_H was a dummy variable; if it equalled 1 , this indicated that two households shared a house, which may have been a factor influencing individuals to leave home and stay in the urban areas.

\subsection{Community factors}

This study used the variables of access to market or the distance from hospital to express the accessibility of a household to public infrastructure. Here, the variable of hospital includes hospitals or clinics. In the study area, there are often a hospital and several clinics in a town. These variables have also been used in previous studies. For instance, Gray (2009) uses the variables of distance to road and distance to highway to explain changes in rural out-migration in the Southern Ecuadorian Andes. In the study area, firewood collection has always been an important factor affecting the livelihood of local rural residents, as firewood is an important fuel. Thus, these three variables were used in this study (Table 1).

\subsection{County difference}

As discussed above, there were considerable differences between the two counties in spatial location (Figure 1). Wulong County borders the capital city of Chongqing, while Youyang County is more distant. This study used a dummy variable to express the difference in location (Table 1). 
In addition, by comparing the differences in age structure before and after migration, those people aged around 35 years had the highest migration rate (Figure 2). Moreover, Figure $2 b$ also shows that rural residents aged under 35 were significantly different from those aged over 35 . Therefore, the total population was divided into two groups: a young group aged between 16 and 35 and an older group aged between 36 and 65 with 397 and 361 residents, respectively. Table 2 shows the characteristics of the two groups of labourers. Based on the division, two linear regression models were used to estimate the determinants of LSCMU: Model 1 and Model 2 for the young and older groups, respectively.

In this study area, according to our survey data, more than half of the migrants worked in other provinces (Table 3); however, it is not easy to

(a)

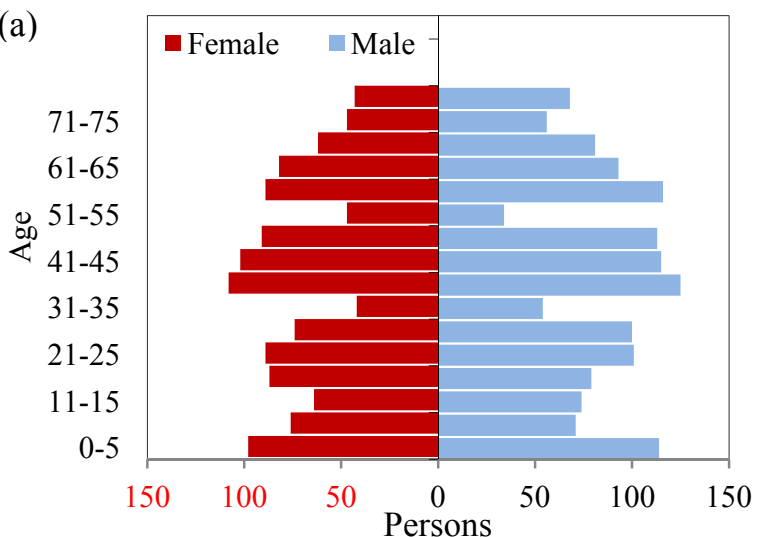

collect information related to urban areas. Therefore, the investigation was mainly carried out in rural areas and did not consider urban factors affecting LSCMU, on the assumption that urban areas, as a whole, provide equal job opportunities for every migrant.

\section{Results}

Table 2 shows that the value of LSCMU was about 225 days per year for the young group, which was much longer than for the old group. To shed light on factors affecting LSCMU, the variables in the young and old groups were entered into linear regression Models 1 and 2, using the SPSS software package (Table 2).

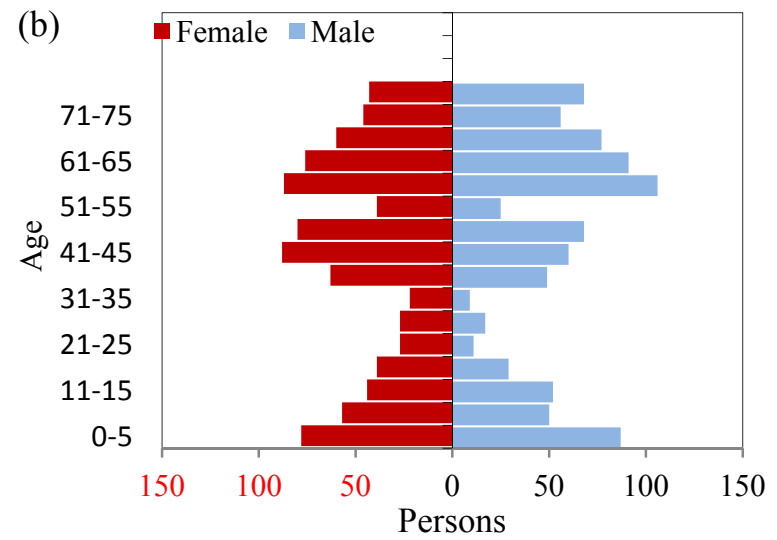

Figure 2 Differences in age structure before migration (a) and after migration (b) in the two groups.

Table 2 Descriptive statistics of all variables used in the regression analysis

\begin{tabular}{|c|c|c|c|c|c|c|}
\hline \multirow{2}{*}{ Variable group } & \multirow{2}{*}{ Code of variable } & \multirow{2}{*}{ Range } & \multicolumn{2}{|c|}{ Model 1 ( $16-35$ years) } & \multicolumn{2}{|c|}{ Model 2 (36-65 years) } \\
\hline & & & Mean & Standard deviation & Mean & Standard deviation \\
\hline Dependent variable & $L S C M U$ (days) & $0-365$ & 224.73 & 117.90 & 173.78 & 149.81 \\
\hline \multirow{6}{*}{ Individual factors } & Gender & $0-1$ & 0.64 & 0.48 & 0.75 & 0.44 \\
\hline & Healthy & $1-4$ & 1.10 & 0.34 & 1.43 & 0.66 \\
\hline & Age & $1-5$ & $25 \cdot 39$ & 4.76 & $45 \cdot 91$ & 8.32 \\
\hline & Education & $1-5$ & 3.04 & 0.88 & 2.32 & 0.74 \\
\hline & Training & $0-1$ & 2.39 & 0.89 & 2.73 & 0.6 \\
\hline & Marriage & $0-1$ & 0.5 & 0.5 & 0.93 & 0.26 \\
\hline \multirow{5}{*}{ Family factors } & Size & & 4.98 & 1.48 & 4.75 & 1.68 \\
\hline & $A r a b \_p e r$ & & 2199.30 & 3087.89 & 2480.23 & 4569.75 \\
\hline & Parcel_A & $1-4$ & 1075.56 & 1312.31 & 1142.07 & 1397.81 \\
\hline & Hou_per & & 39.44 & 28.98 & 41.11 & 32.18 \\
\hline & Share_H & $0-1$ & 0.19 & 0.39 & 0.19 & 0.39 \\
\hline \multirow{3}{*}{ Community factors } & D_market & & 10.00 & 7.12 & 9.56 & 7.12 \\
\hline & D_hospital & & 6.01 & 4.79 & 5.49 & 4.56 \\
\hline & D_wood & & 1812.45 & 3739.40 & 1388.65 & 1071.30 \\
\hline County difference & County_code & $0-1$ & 0.59 & 0.49 & 0.57 & 0.50 \\
\hline
\end{tabular}




\begin{tabular}{|c|c|c|c|c|c|c|c|c|c|c|c|}
\hline individual & 2 & & ce & rc & ula & gra & & & & & \\
\hline $\begin{array}{l}\text { factors, the Age and } \\
\text { Training }\end{array}$ & & & $\begin{array}{l}\text { Cou } \\
\text { nam }\end{array}$ & & & ces & $\begin{array}{l}\text { Oth } \\
\text { in C }\end{array}$ & $\begin{array}{l}\text { ounties } \\
\text { lging }\end{array}$ & $\begin{array}{l}\text { Other to } \\
\text { local cou }\end{array}$ & & $\begin{array}{l}\text { Local } \\
\text { towns }\end{array}$ \\
\hline significantly & Num & & Wul & & 112 & & 97 & & 25 & & 28 \\
\hline ISCMU in both models & migrants (per & & Youy & ang & 284 & & 13 & & 35 & & 14 \\
\hline The Training variable had & $\begin{array}{l}\text { Total migrants } \\
\text { (persons) }\end{array}$ & & & & 396 & & 110 & & 60 & & 42 \\
\hline dependent variable in both & Table 4 Estin & Fe & of the & regr & essic & mo & el for & gration & & & \\
\hline 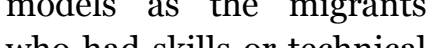 & & & Moc & el 1 & $(16-$ & yeal & & Mo & del $2(36-6$ & yea & \\
\hline who had skills or technical & & S-c & coef. & & $\mathrm{t}$ & & ig. & S-coef. & $\mathrm{t}$ & & Sig. \\
\hline abilities stayed in urban & Individual facto & & & & & & & & & & \\
\hline areas for a longer period & Gender & 0.07 & & 1.40 & & 0.16 & & 0.089 & 1.746 & 0.0 & $82 *$ \\
\hline each year. However, the & Healthy & -0.0 & 053 & -1. & 072 & $0.2 \varepsilon$ & & -0.101 & -1.844 & 0.0 & 66 * \\
\hline Age variable exerted a & Age & 0.17 & & 2.9 & & 0.0 & $3 * * *$ & -0.293 & -5.126 & 0.0 & $0^{* * *}$ \\
\hline positive effect in Model 1 & Education & 0.03 & & 0.6 & & 0.5 & & 0.051 & 0.977 & 0.3 & \\
\hline and a negative effect in & Training & -0.1 & & -2 & 490 & 0.0 & $3 * *$ & -0.195 & -3.785 & 0.0 & $\mathrm{OO} * * *$ \\
\hline Model 2. This suggested & Marriage & -0.0 & 059 & -0. & 945 & 0.3 & & -0.051 & -0.931 & 0.3 & \\
\hline that the length of stay in & Family factors & & & & & & & & & & \\
\hline Lilat tine lengin or stay 111 & Size & -0.0 & 039 & -0. & 661 & 0.5 & & 0.086 & 1.375 & 0.17 & \\
\hline urban areas increased & Arab_per & -0.1 & & -1.2 & 456 & 0.14 & & -0.028 & -0.350 & 0.72 & \\
\hline increasing age in $\mathrm{N}$ & Parcel_A & 0.15 & & 1.53 & & 0.12 & & 0.058 & 0.724 & 0.4 & \\
\hline whereas the opposite & Hou_per & 0.04 & & 0.8 & & 0.37 & & 0.042 & 0.717 & 0.4 & \\
\hline tendency was observed in & Share_H & 0.09 & & 1.88 & & 0.0 & & 0.054 & 1.026 & 0.3 & \\
\hline Model 2. & Community & ors & & & & & & & & & \\
\hline The Gender variable & D_market & -0.0 & 064 & -1.1 & 135 & 0.2 & & -0.068 & -1.186 & 0.2 & \\
\hline influenced LSCMU in & D_hospital & 0.17 & & 3.0 & & 0.0 & $2 * * *$ & 0.061 & 1.103 & 0.2 & \\
\hline Model 2. This indicated & D_wood & -0.0 & 033 & -0. & 662 & 0.5 & & -0.017 & -0.335 & 0.7 & \\
\hline that, in the older gr & County differ & & & & & & & & & & \\
\hline men remained longer in & County_code & -0.2 & & -4 & 032 & 0.0 & $0 * * *$ & -0.017 & -0.287 & 0.77 & \\
\hline
\end{tabular}

urban areas each year than women. The influence in

Model 1 was not significant. Like the Gender variable, the Health variable affected LSCMU in Model 2 at the 10\% significance level and was not significant in Model 1. It was noticeable that the Marriage and Education variables had no influence on LSCMU in either model (Table 4).

Among the family factors, only the Share_H variable affected the dependent variable in Model 1 at the $10 \%$ significance level. The rest of the variables were non-significant in both models (Table 4).

The D_hospital and County_code variables influenced LSCMU in Model 1 at the $1 \%$ significance level. The former had a positive effect, whereas the latter was negative. In Model 2, these effects were not significant.

In addition, in a multiple regression analysis, standardization of coefficients is often used to answer the question of which of the independent variables has a greater influence on the dependent variable. In Model 1, standardized coefficients for the County_code variable were the largest, which meant that the former played the most important role in affecting LSCMU. In Model 2, the most important role was the Age, followed by the Training variable.

\section{Discussion}

In mountainous areas, job opportunities are scarce and income from agricultural production is often much lower than non-agricultural income (Shao et al. 2005). Attracted by rapid economic development and the more attractive lifestyles on offer in urban areas, the rural population leaves home and moves to such urban areas. However, in the cities, they encounter the burden of higher living costs. Therefore, these migrants must make the decision whether to stay in urban areas, and 
how long to remain there. According to the regression results, the decisions were mainly affected by individual factors, including the variables of Gender, Age and Health (Table 4). Furthermore, the effects were quite different between the two models.

\subsection{The Effects of Individual factors on LSCMU}

Model 2 shows that the Gender variable had an effect on the dependent variable, and women stayed a shorter time in urban areas than men. The existing literature also supports this. For instance, Haan (1997) thinks that migration is a predominantly male behaviour and this pattern of single-male migration is not caused by employers' demand for male labour, and has relationships with family strategy in India. This is similar to China. Since many migrants leave their children behind, women aged over 35 often have to take care of children and aging parents at home. However, in Model 1 for the young group, this sex difference was not significant. The main reason is that, like young men, young women tend to leave the rural areas to work in urban areas.

Among the individual factors, the Age variable exerted different effects on LSCMU in the two models. In Model 1, LSCMU increased with increasing age, whereas the opposite tendency was observed in Model 2. The data also showed that, for the circular migrants aged between 34 and 36, the value of LSCMU was 236 days per year, whereas the corresponding value for other people was 199 days per year. Similarly, the rate of migration was the highest in this age group. For the rural residents aged between 34 and 36 , about $61 \%$ of them left home to work in cities or towns (Figure 3). Model 1 suggests that young migrants lacked job information and practical skills, which commonly led to unemployment. In addition, for migrants who were too old, many types of job were dangerous or unsuitable. So, the relationship between age and LSCMU were nonlinear. This is consistent with the findings in existing literature (Hu et al. 2011; Zhang et al. 2014), which suggests that rural migrants who are either too young or too old do not accumulate sufficient wealth in the cities. Thus, the relationship between age and the probability of migration was nonlinear and

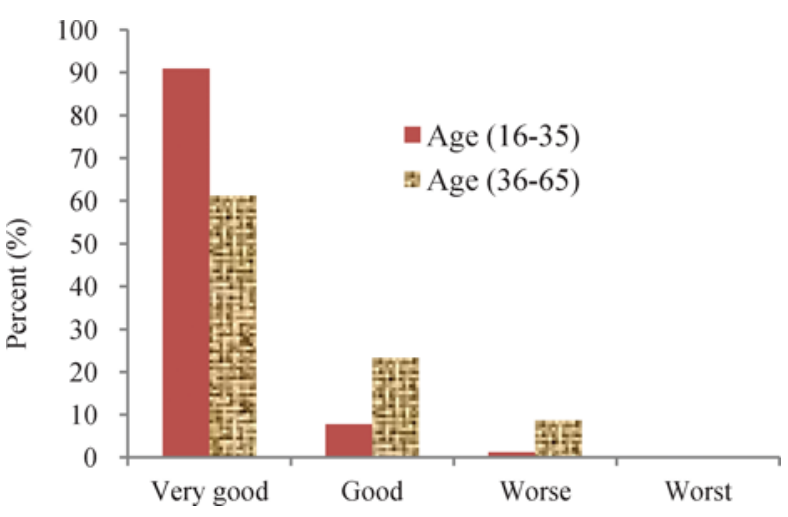

Figure 3 The health status of the two groups of workers from the study area.

exhibited an inverse U-shaped curve ( $\mathrm{Hu}$ et al. 2011).

Rural destinations have lost younger people, resulting over time in an aging rural population. This phenomenon has occurred in many developed countries such as the United States and countries in Europe (Thissen et al. 2010; Glasgowa and Brown 2012). However, in mountain areas, the problem of rural aging is more serious than in other rural areas, because the basic infrastructure (such as sanitary conditions) is poor and the natural environment is harsh, which greatly affects the livelihood of older rural residents. Furthermore, it is very difficult to improve the basic infrastructure in high mountain regions.

In Model 2, the Health variable also significantly affected LSCMU. For the older group, health conditions were worse than for the younger generation. About $90 \%$ of workers were in very good health in the young group, whereas in the older group this decreased to $61 \%$. Thus, the health conditions of circular migrants affected LSCMU in Model 2, but had no obvious effects in Model 1. Those with health problems often stayed in rural areas. As mentioned above, rural locations have lost younger and stronger individuals and seen an increase in older and weaker individuals.

The Training variable significantly influenced the dependent variable in both models. The techniques or special skills acquired through training can be used directly in jobs such as decorating or cooking. Furthermore, skills and techniques not only increase opportunities for circular migrants to obtain jobs (Fan and Stark 2008; Seto 2011), but also increase their income. In the study areas, the monthly income of trained 
migrants was 2343 yuan in 2011, while the corresponding income for untrained migrants was 2107 yuan. In the future, the Chinese central government will emphasize the necessity of encouraging the transition of circular migrants to permanent ones. During this process, job training for circular migrants should be strengthened in various ways, including government institutes, vacation schools and the involvement of master workers.

In some research, education often plays an important role in the process of migration (Lanzona 1998; Liu 2008; Sun and Fan 2013). However, in this study, the influence of education on LSCMU was not significant; Figure 4 explains this further. There were no obvious differences between circular migrants from different education levels, excluding those who were illiterate. They stayed in urban areas for much shorter than other migrants. This conclusion is similar to the results of Liu et al. (2014) with their survey data from the mountainous and upland areas of Sichuan province near to Chongqing, who also suggest that the variable of education has no significant effect on the selection of work place.

Furthermore, in previous literature (Haan 1997), marital status often determined the timing of circular migrants. In our study, the Marriage variable had no significant effect on the dependent variables. In present-day China, wives often accompany husbands to urban areas or towns, especially when the couples are young.

\subsection{The Effects of Family Factors on LSCMU}

Compared with individual factors, family factors exerted much weaker effects on LSCMU. Among the household factors, only the Share_H variable affected the dependent variable in Model 1 at the $10 \%$ significance level. In some rural villages in remote mountain areas, two families might share the same house. Such poor living conditions may force young people to leave home and stay in urban areas for a greater number of days per year.

Contrary to our expectations, other variables related to family had no significant effects on the dependent variable, including household size, living area per capita, arable land per capita and the average area of arable land parcels. This is not consistent with empirical results. For instance,
Haan (1997) thinks that the role of family (such as caste and land ownership) is crucial in migration decisions in the case study of India in the twentieth century. One of the main reasons for this discrepancy may be the small variations in per capita arable land among households, resulting from equal allocation of arable land in China (Zhang and Song 2003).

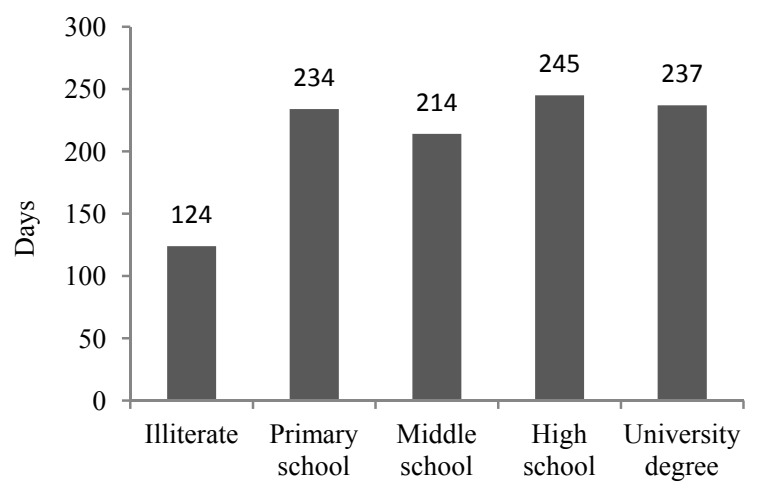

Figure 4 The length of urban stay of circular migrants of different education levels from the study area.

\subsection{The Effects of Community Factors on LSCMU}

In the Community group, the D_hospital variable had a positive effect on LSCMU at the $1 \%$ significance level in Model 1. Families living further from hospital were often located in more remote mountain areas. This made their livelihood more difficult, and young workers preferred to stay longer in urban areas. In contrast, the D_Market variable had no significant effect on the dependent variable. The main reason may be that there are several hospitals or clinics, whereas there is only a market in a town in China. So, the D_hospital variable can better reflect the accessibility of a household to public infrastructure.

Contrary to expectations, the $D \_$wood variable had no significant effects on LSCMU. In the past, biofuel played an important role in the livelihood of rural residents in mountain areas. At present, this role is becoming continuously weaker because of the increasing use of other forms of energy, including electricity, coal and gas.

The effects of the County_code variable were negative, which meant that the circular migrants from Wulong County stayed in urban areas for a 
longer period compared with those from Youyang County. Actually, this variable expresses the locational advantage of Wulong County. This county borders the capital city of Chongqing municipality, which can provide more employment opportunities for circular migrants (Figure 1). This makes it easier for Wulong workers to find jobs; as a result, migrants from the county can work in urban areas for a greater number of days per year. Furthermore, in Model 1, this variable played the most important role in affecting LSCMU, because the standardized coefficients for the variable were the largest (Table 4). This supports the existing conclusion that migration is a process of selection, and positive locations can increase outward migration (Gray 2009; Sun and Fan 2013).

\section{Summary and Conclusions}

This study focused on the issue of the length of stay in urban areas of circular migrants, using investigative data from eight villages in mountain areas in Chongqing, China. The results showed that the length of stay of the young and old groups in urban areas was 225 and 174 days per year, respectively.

The length of stay was mainly affected by individual factors, including the variables of Age, Gender and Health. In the young group, the length of stay in urban areas increased with increasing age, whereas the opposite tendency was observed in the older group. The variables of Gender and Health had significant effects on the dependent variable in the old group, but the effects were not obvious in the young group. The variables of Marriage and
Education, which have always been regarded as important factors affecting rural-urban migration, did not significantly influence the dependent variable in either model in this study.

Family factors, including household size and arable land per capita, had no significant effects on the dependent variable, especially in the old group. In this study, Wulong County borders the capital city of Chongqing municipality, which provides more job information for circular migrants. This became the most important factor affecting the dependent variable in the young group. In the older group, the most important factor was the Age variable.

The variable of Training significantly influenced the dependent variable in both models. During the process of urbanization, we suggest that job training for circular migrants should be strengthened in various ways, including via government institutes, vacation schools and master workers, because the techniques or special skills learned from training can be used both directly in jobs and also through increasing employment opportunities. This can, therefore, influence the length of stay of circular migrants in urban areas.

\section{Acknowledgements}

This work was supported by the Natural Science Foundation of China (Grant Nos. 41161140352 and 41271119) and the National Basic Research Program of China (Grant No. 2015CB452705). Valuable comments and suggestions from anonymous reviewers are greatly appreciated.

\section{References}

Bjarnasona T, Thorlindsson T (2006) Should I stay or should I go? Migration expectations among youth in Icelandic fishing and farming communities. Journal of Rural Studies 22: 290300. DOI:10.1016/j.jrurstud.2005.09.004

Chang KC, Wen M, Wang G (2011) Social capital and work among rural-to-urban migrants in China. Asian Population Studies 7(3): 275-292. DOI:10.1080/17441730.2011.608989

Ding J, Liu Z, Cheng D, et al. (2005) Areal differentiation of inter-provincial migration in China and characteristics of the flow field. Acta Geographica Sinica 60(1): 106-114. DOI: 10.3321/j.issn:0375-5444.2005.01.012

Easterlin RA, Angelescu L, Zweig JS (2011) The impact of modern economic growth on urban-rural differences in subjective well-Being. World Development 39(12): 2187-2198. DOI: $10.1016 /$ j.worlddev.2011.04.015

Elkan W (1967) Circular migration and growth of town in East Africa. International Labour Review 96 (6): 581-589.

Fan CS, Stark O (2008) Rural-to-urban migration, human capital, and agglomeration. Journal of Economic Behavior \& Organization 68: 234-247. DOI: 10.1016/j.jebo.2008.04.003 Fang YP, Fan J, Shen MY, Song MQ (2014) Sensitivity of livelihood strategy to livelihood capital in mountainareas: Empirical analysis based on different settlements in the upperreaches of the Minjiang River. Ecological Indicators 38:225-235. DOI: 10.1016/j.ecolind.2013.11.007 
Feng Z, Zhang P, Yang Y (2003)The scale of land conversion from farmland to forest or grassland, the grain response to it, and the relevant proposals in Northernwest China. Geographical Research (In Chinese) 22(1): 105-113.

Frayne B (2004) Migration and urban survival strategies in Windhoek, Namibia. Geoforum 35: 489-505. DOI: 10.1016/ j.geoforum.2004.01.003

Gellrich M, Zimmermann NE (2007) Investigating the regionalscale pattern of agricultural land abandonment in the Swiss mountains: A spatial statistical modelling approach. Landscape and Urban Planning 79: 65-76. DOI: 10.1016/ j.landurbplan.2006.03.004

Glasgowa N, Brown DL (2012)Rural ageing in the United States: Trends and contexts. Journal of Rural Studies 28: 422-431. DOI: $10.1016 /$ j.jrurstud.2012.01.002

Gray CL (2009) Environment, land, and rural out-migration in the Southern Ecuadorian Andes. World Development 37(2): 457-468. DOI: $10.1016 /$ j.worlddev.2008.05.004

Groom B, Grosjean P, Kontoleon A, et al. (2009) Relaxing rural constraints: a 'win-win' policy for poverty and environment in China? Oxford Economic Papers 62: 132-156. DOI: 10.1093/ oep/gppo21

Haan AD (1997) Migration as family strategy: Rural-Urban Labor Migration in India during the Twentieth Century. The History of The Family 2(4): 481-505.

Cordell DD, Gregory JW, Piche V (1996) Hoe and wage, a social history of circular migration in Africa,Boulder, Colo, West View Press.

Hu F, Xu Z, Chen Y (2011) Circular migration, or permanent stay? Evidence from China's rural-urban migration. China Economic Review 22: 64-74. DOI: 10.1016/j.chieco.2010.09.007

Iacovou M (2010) Leaving home: Independence, togetherness and income. Advances in Life Course Research 15: 147-160. DOI:10.1016/j.alcr.2010.10.004

Izquierdo AE, Grau HR (2009) Agriculture adjustment, landuse transition and protected areas in Northwestern Argentina. Journal of Environmental Management 90: 858-865. DOI:10.1016/j.jenvman.2008.02.013

Knight J, Gunatilaka R (2010) Great expectations? The subjective well-being of rural-urban migrants in China. World Development 38(1): 113-124. DOI:10.1016/j.worlddev. 2009.03.002

Lanzona LA (1998) Migration, self-selection and earnings in Philippine rural communities. Journal of Development Economics 56: 27-50.

Liu Z (2008) Human capital externalities and rural-urban migration: Evidence from rural China. China Economic Review 19: 521-535. DOI:10.1016/j.chieco.2008.04.001

Liu S, Xie F, Zhang H, Guo S (2014) Influences on rural migrant workers' selection of employmentlocation in the mountainous and upland areas of Sichuan, China. Journal of Rural Studies 33:71-81. DOI: 10.1016/j.jrurstud.2013.11.001

Mulian K, Grosjean P, Kontoleon A (2010) Land tenure arrangements and rural-urban migration in China. World Development 39(1): 123-133. DOI: 10.1016/j.worlddev.2010. 08.009
Seeborg MC, Jin Z, Zhu Y (2000)The new rural-urban labor mobility in China: Causes and implications. Journal of SocioEconomics 29: 39-56.

Seto KC (2011) Exploring the dynamics of migration to megadelta cities in Asia and Africa: Contemporary drivers and future scenarios. Global Environmental Change 21S: S94S107. DOI: 10.1016/j.gloenvcha.2011.08.005

Shao JA, Wei CF, Xie DT(2005)Mountain land use planning of metropolitan suburbs: the case of the Jinyun mountain and its surrounding area, Chongqing, China. Journal of Mountain Science 2(2): 116-128. DOI: 10.1007/BFo2918327

Silveira JJ, Ndola ALE, Penna TJP (2006) Agent-based model to rural-urban migration analysis. Physica A 364: 445-456. DOI: 10.1016/j.physa.2005.08.055

Sitzia T, Semenzato P, Trentanovi G (2010) Natural reforestation is changing spatial patterns of rural mountain and hill landscapes: A global overview. Forest Ecology and Management 259: 1354-1362. DOI: 10.1016/j.foreco.2010.01. 048

Sun M, Fan CC (2013) China's permanent and temporary migrants: differentials and changes, 1990-2000. The Professional Geographer 63(1): 92-112. DOI: 10.1080/ 00330124.2010.533562

Thissen F, Fortuijn JD, Strijker D, Haartsen T (2010) Migration intentions of rural youth in the Westhoek, Flanders, Belgium and the Veenkoloniën, the Netherlands. Journal of Rural Studies 26: 428-436. DOI: 10.1016/j.jrurstud.2010.05.001

Tzanopoulos J, Kallimanis AS, Bella I, et al. (2011) Agricultural decline and sustainable development on mountain areas in Greece: sustainability assessment of future scenarios. Land Use Policy 28: 585-593. DOI: 10.1016/j.landusepol.2010.11.007

Wang C, Yang Y, Zhang Y (2012) Rural household livelihood change, fuelwood substitution, and hilly ecosystem restoration: Evidence from China. Renewable and Sustainable Energy Reviews 16: 2475-2482. DOI: 10.1016/j.rser.2012.01.070

Wang X, Lu C, Fang J, Shen Y (2007) Implications for development of grain-for-green policy based on cropland suitability evaluation in desertification-affected north China. Land Use Policy 24: 417-424. DOI: 10.1016/j.landuse pol.2006.05.005

Yu X, Li Y, Lei J (2013)Analysis on China's provincial population migration and its impact on regional economic development since the new century. Population Journal 35(3): 5-14. DOI: 10.3969/j.issn.1004-129X.2013.03.001

Zhang KH, Song S (2003) Rural-urban migration and urbanization in China: Evidence from time-series and crosssection analyses. China Economic Review 14: 386-400. DOI: 10.1016/j.chieco.2003.09.018

Zhang P, Shao G, Zhao G, et al. (2000) China's Forest Policy for the 21st Century. Science 288: 2135-2136. DOI: 10.1126/ science.288.5474.2135

Zhang Y, Li X, Song W (2014) Determinants of cropland abandonment at the parcel, household andvillage levels in mountain areas of China: A multi-level analysis. Land Use Policy 41: 186-192. DOI: 10.1016/j.landusepol.2014.05.011 